\title{
Correction to: Alison Butler: papers in celebration of her 2018 ACS Alfred Bader Award in Bioorganic or Bioinorganic Chemistry
}

\author{
Lawrence Que Jr ${ }^{1}$
}

Published online: 7 December 2018

(c) Society for Biological Inorganic Chemistry (SBIC) 2018

\section{Correction to: \\ JBIC Journal of Biological Inorganic Chemistry https://doi.org/10.1007/s00775-018-1618-9}

"In the original online publication, the Foreword was incorrectly attributed. The correct author is Lawrence Que, Jr."

In reference 17 the names of the authors were incorrectly published as “17. Sono M, Suna S, Modia A, Hargrove MS et al. (2018) J Biol Inorg Chem". The correct names of the authors are "17. Sono M, Sun S, Modi A, Hargrove MS et al. (2018) J Biol Inorg Chem.”

The original article can be found online at https://doi.org/10.1007/ s00775-018-1618-9.

Lawrence Que Jr

jbic@umn.edu

1 Department of Chemistry, University of Minnesota, 207

Pleasant Street SE, Minneapolis, MN 55455-0431, USA 